\title{
Exposure to prescription opioid analgesics in utero and risk of neonatal abstinence syndrome: population based cohort study
}

\section{Citation}

Desai, Rishi J, Krista F Huybrechts, Sonia Hernandez-Diaz, Helen Mogun, Elisabetta Patorno, Karol Kaltenbach, Leslie S Kerzner, and Brian T Bateman. 2015. “Exposure to prescription opioid analgesics in utero and risk of neonatal abstinence syndrome: population based cohort study." BMJ : British Medical Journal 350 (1): h2102. doi:10.1136/bmj.h2102. http://dx.doi.org/10.1136/ bmj.h2102.

\section{Published Version}

doi:10.1136/bmj.h2102

\section{Permanent link}

http://nrs.harvard.edu/urn-3:HUL.InstRepos:16120888

\section{Terms of Use}

This article was downloaded from Harvard University's DASH repository, and is made available under the terms and conditions applicable to Other Posted Material, as set forth at http:// nrs.harvard.edu/urn-3:HUL.InstRepos:dash.current.terms-of-use\#LAA

\section{Share Your Story}

The Harvard community has made this article openly available.

Please share how this access benefits you. Submit a story.

Accessibility 


\title{
Exposure to prescription opioid analgesics in utero and risk of neonatal abstinence syndrome: population based cohort study
}

\author{
Rishi J Desai, ${ }^{1}$ Krista F Huybrechts, ${ }^{1}$ Sonia Hernandez-Diaz, ${ }^{2}$ Helen Mogun, ${ }^{1}$ Elisabetta Patorno, ${ }^{1}$ \\ Karol Kaltenbach, ${ }^{3}$ Leslie S Kerzner, ${ }^{4}$ Brian T Bateman ${ }^{1,5}$
}

${ }^{1}$ Division of

Pharmacoepidemiology and

Pharmacoeconomics,

Department of Medicine,

Brigham and Women's Hospital

and Harvard Medical School,

Boston, MA 02120, USA

2Department of Epidemiology,

Harvard School of Public Health,

Boston

${ }^{3}$ Department of Pediatrics,

Sidney Kimmel Medical College,

Thomas Jefferson University,

Philadelphia, PA, USA

4 Department of Pediatrics,

Massachusetts General

Hospital, Harvard Medical

School, Boston, MA

${ }^{5}$ Department of Anesthesia,

Critical Care, and Pain Medicine,

Massachusetts General

Hospital, Harvard Medical

School, Boston

Correspondence to: R J Desai

rdesai2@partners.org

Additional material is published

online only. To view please visit

the journal online (http://dx.doi.

org/10.1136/bmj.h2102)

Cite this as: $B M J$ 2015;350:h2102

doi: 10.1136/bmj.h2102

Accepted: 30 March 2015

\begin{abstract}
OBJECTIVE

To provide absolute and relative risk estimates of neonatal abstinence syndrome (NAS) based on duration and timing of prescription opioid use during pregnancy in the presence or absence of additional NAS risk factors of history of opioid misuse or dependence, misuse of other substances, non-opioid psychotropic drug use, and smoking.

DESIGN

Observational cohort study.

SETTING

Medicaid data from 46 US states.

\section{PARTICIPANTS}

Pregnant women filling at least one prescription for an opioid analgesic at any time during pregnancy for whom opioid exposure characteristics including duration of therapy: short term ( $<30$ days) or long term ( $\geq 30$ days); timing of use: early use (only in the first two trimesters) or late use (extending into the third trimester); and cumulative dose (in morphine equivalent milligrams) were assessed.

MAIN OUTCOME MEASURE

Diagnosis of NAS in liveborn infants.

RESULTS

1705 cases of NAS were identified among 290605

pregnant women filling opioid prescriptions, corresponding to an absolute risk of 5.9 per 1000
\end{abstract}

\section{WHAT IS ALREADY KNOWN ON THIS TOPIC}

The use of prescription opioids is increasingly common for treating pain in pregnancy, but the risk to infants as a result of this practice remains largely unknown

Numerous case reports and one small observational cohort study suggest a potential risk of neonatal abstinence syndrome after in utero exposure to therapeutic doses of prescription opioids

The patterns of use of prescription opioids during pregnancy, such as amount, duration, and timing, in elevating the risk of neonatal abstinence syndrome are not well characterized, particularly when additional risk factors are present

\section{WHAT THIS STUDY ADDS}

This large population based cohort study indicates that the risk of neonatal abstinence syndrome is higher in women using long term prescription opioids in the presence of additional risk factors including history of opioid misuse or dependence, alcohol or other drug misuse, exposure to non-opioid psychotropic medications late in pregnancy, and smoking

In comparison, short term use of prescription opioids for treating acute pain during pregnancy is associated with a lower risk of deliveries of infants with with neonatal abstinence syndrome in the absence of other additional risk factors Maternal use of prescription opioids late in pregnancy (through the third trimester) compared to use only in the first two trimesters is associated with greater risk of neonatal abstinence syndrome in infants deliveries ( $95 \%$ confidence interval 5.6 to 6.2 ). Long term opioid use during pregnancy resulted in higher absolute risk of NAS per 1000 deliveries in the presence of additional risk factors of known opioid misuse (220.2 (200.8 to 241.0)), alcohol or other drug misuse (30.8 (26.1 to 36.0)), exposure to other psychotropic medications (13.1 (10.6 to 16.1)), and smoking (6.6 (4.3 to 9.6)) than in the absence of any of these risk factors (4.2 (3.3 to 5.4)). The corresponding risk estimates for short term use were 192.0 (175.8 to 209.3), 7.0 (6.0 to 8.2), 2.0 (1.5 to 2.6), 1.5 (1.0 to 2.0), and 0.7 (0.6 to 0.8$)$ per 1000 deliveries, respectively. In propensity score matched analyses, long term prescription opioid use compared with short term use and late use compared with early use in pregnancy demonstrated greater risk of NAS (risk ratios 2.05 (95\% confidence interval 1.81 to 2.33 ) and 1.24 (1.12 to 1.38), respectively).

\section{CONCLUSIONS}

Use of prescription opioids during pregnancy is associated with a low absolute risk of NAS in the absence of additional risk factors. Long term use compared with short term use and late use compared with early use of prescription opioids are associated with increased NAS risk independent of additional risk factors.

\section{Introduction}

Neonatal abstinence syndrome (NAS) is a serious medical condition experienced by the newborn after in utero exposure to psychotropic substances. ${ }^{1}$ The symptoms of neonatal abstinence syndrome can range from relatively minor behavioral problems such as feeding, sleeping, and temperature regulation difficulties to major problems such as seizures, failure to thrive, and respiratory distress. Neonatal abstinence syndrome is associated with substantially increased healthcare expenditures and its incidence has been on the rise in the United States. ${ }^{2}$ In utero exposure to opioids is reported to account for a large proportion of cases of total neonatal abstinence syndrome. ${ }^{3}$

Prior studies have reported a high incidence of neonatal abstinence syndrome (42-58\%) in infants born to mothers using illicit opioids ${ }^{4}$ and infants born to opioid dependent mothers on maintenance therapy with methadone or buprenorphine. ${ }^{56}$ However, recent studies from both Europe and the US indicate high use of licit prescription opioids for pain management during pregnancy. Data from a population based registry in Norway revealed that $6 \%$ of pregnant women filled at least one opioid prescription between 2004 and 2006. ${ }^{7}$ In all, $14 \%$ to $22 \%$ of women are reported to have filled at least one prescription for an opioid analgesic during 
pregnancy in the US, with prevalence of use in some states as high as $41 \% .{ }^{8}$ While data specific to prescription opioid use among pregnant women are not available for countries other than Norway and the US, data from the general population suggest increasing use of prescription opioids in Canada, ${ }^{10}$ Germany, ${ }^{11}$ Israel, ${ }^{12}$ and the United Kingdom. ${ }^{13}$ Despite evidence of high and increasing use, few studies have described estimates for the risk of neonatal abstinence syndrome in infants after in utero exposure to prescription non-maintenance opioid analgesics. Existing research consists of numerous case reports that document neonatal withdrawal symptoms after exposure to therapeutic doses of various prescription opioids ${ }^{14-17}$ and a small observational study from a single medical center that reports symptoms of neonatal abstinence syndrome in 10 of the 167 (5.6\%) infants exposed to in utero chronic ( $\geq 30$ days) prescription opioids. ${ }^{18}$ No population based estimates are available for the risk of neonatal abstinence syndrome in infants born to mothers using prescription opioid analgesics during pregnancy.

Moreover, several additional in utero exposures that may increase the likelihood or severity of neonatal abstinence syndrome have been identified in studies of pregnant women with addiction. These exposures include alcohol misuse or non-opioid illicit drugs of misuse, ${ }^{1920}$ psychotropic prescription medications other than opioids, notably selective serotonin reuptake inhibitors and benzodiazepines, ${ }^{321-25}$ and tobacco. ${ }^{26-28}$ The impact of these additional exposures on the risk of neonatal abstinence syndrome in infants born to pregnant women using prescription opioid analgesics is also not well understood.

Therefore, using a nationwide cohort of Medicaid enrolled pregnant women, our objective was to provide absolute and relative risk estimates of neonatal abstinence syndrome based on prescription opioid duration and timing of use during pregnancy in the presence or absence of additional risk factors for neonatal abstinence syndrome, including history of opioid misuse or dependence, misuse of other substances, non-opioid psychotropic drug use, and smoking.

\section{Methods}

Data source and study population

Data for this study were drawn from the Medicaid Analytical eXtract files for enrollees in 46 US states and Washington, DC for the period of 2000 to 2007. Data for Arizona, Connecticut, Michigan, and Montana were not used because of either data unavailability or incomplete data. These files contain information on demographics, diagnoses and procedures performed during outpatient visits or inpatient stays, and outpatient filled prescription drugs for Medicaid enrollees. The use of this de-identified database for research was approved by the institutional review board of Brigham and Women's Hospital.

The study population consisted of women aged 12 to 55 years with completed pregnancies resulting in liveborn infants. Methods used for linking mothers with their infants have been described in detail previously. ${ }^{29}$
We estimated the date of last menstrual period based on the delivery date combined with a validated algorithm. ${ }^{30}$ We required women to have continuous Medicaid eligibility beginning from the date of last menstrual period to the 30th day after delivery in order to ensure the completeness of their healthcare claims. For inclusion in our study cohort, we further required women to have filled at least one outpatient prescription for an opioid analgesic at any time during pregnancy. The following prescription opioid analgesics were considered: codeine, dihydrocodeine, fentanyl, hydrocodone, hydromorphone, levorphanol, meperidine, morphine, oxycodone, oxymorphone, pentazocin, propoxyphene, tapentadol, and tramadol.

\section{Patient involvement}

Since this study was conducted using de-identified patient data, there was no patient involvement.

\section{Additional risk factors for neonatal abstinence} syndrome and identification of the study groups

For all women with exposure to a prescription opioid analgesic, we defined the following four major additional risk factors for neonatal abstinence syndrome:

- Documented history of opioid misuse or dependence: use of illicit opioids (mainly heroin) or maintenance therapy prescription opioids in women who are dependent on opioids during pregnancy is widely recognized to be the most important risk factor for neonatal abstinence syndrome. ${ }^{4-631}$ Therefore, we identified women with ICD-9 (international classification of diseases, 9th revision) codes specific to opioid misuse and opioid dependence in either inpatient or outpatient maternal claims at any time during pregnancy (appendix 1). Further, since methadone and buprenorphine are indicated for use in medication assisted maintenance therapy in pregnant women with opioid misuse or dependence, we identified women with at least one filled prescription of either of these agents during pregnancy as an indicator for opioid misuse or dependence.

- Documented history of alcohol misuse or non-opioid drug misuse: misuse of non-opioid drugs (for example, cocaine) as well as alcohol has been found to result in worse symptoms of neonatal abstinence syndrome in infants born to mothers who misuse these substances. ${ }^{19}{ }^{20}$ Therefore, we used ICD-9 codes for misuse or dependence on alcohol or other non-opioid drugs in either inpatient or outpatient maternal claims at any time during pregnancy to define history of alcohol misuse or non-opioid drug misuse (appendix 1).

- Use of prescription psychotropic medications in the third trimester: prior research has implicated a variety of psychotropic agents as potential risk factors for neonatal abstinence syndrome. ${ }^{3}$ 21-25 We identified prescription dispensings of the following psychotropic medications during the 90 days prior to delivery: tricyclic antidepressants, selective norepinephrine (noradrenaline) re-uptake inhibitors, selective 
serotonin reuptake inhibitors, benzodiazepines, non-benzodiazepine anxiolytics and hypnotics, anticonvulsants, and antipsychotics.

- Tobacco use: maternal smoking has also been reported to be associated with a higher likelihood of developing neonatal abstinence syndrome. ${ }^{27}$ Smoking is also known to worsen symptoms of neonatal abstinence syndrome in women on methadone maintenance therapy. ${ }^{26}{ }^{28}$ Therefore, we identified history of maternal smoking based on the presence of ICD-9 diagnosis codes for tobacco related conditions, or Current Procedure Terminology codes for smoking counseling in inpatient or outpatient claims (appendix 1), or prescriptions of anti-smoking drugs (varenicline, bupropion, nicotine) in pharmacy claims.

Based on the presence or absence of these additional risk factors, five mutually exclusive groups were created hierarchically in decreasing order of the hypothesized strength of association with neonatal abstinence syndrome. The first group included pregnant women with a history of opioid misuse or dependence; the second group included pregnant women with a history of alcohol or non-opioid drug misuse or dependence (but no history of opioid misuse or dependence); the third group included women who filled at least one prescription for a non-opioid psychotropic medication during the three months prior to the delivery (but no history of opioid, alcohol, or non-opioid drug misuse or dependence); the fourth group included women with a history of smoking (but neither a history of opioid, alcohol, or non-opioid drug misuse or dependence nor use of non-opioid psychotropic medication three months prior to the delivery); and the fifth group included women who did not have any of the above discussed additional risk factors for neonatal abstinence syndrome.

\section{Prescription characteristics of opioid exposure}

Exposure to prescription opioids was characterized in terms of duration, timing of use during pregnancy, and total cumulative exposure:

- Duration of prescription opioid use: we defined the duration of use of prescription opioid by accumulating total day supply across different prescriptions for these agents between the last menstrual period and the delivery date. Based on the accumulated days, we dichotomized duration of use of prescription opioids into short term use ( $<30$ days) and long term use ( $\geq 30$ days).

- Timing of use of prescription opioids during pregnancy: some authors have suggested that exposure to prescription opioids late in the pregnancy may be associated with a higher risk of neonatal abstinence syndrome compared to early exposure..$^{32} 33$ We therefore categorized opioid exposure based on the timing of the prescription fills during pregnancy: early exposure included women who had filled prescriptions only in the first two trimesters but who did not have a newly dispensed opioid prescription in the last 90 days before delivery; late exposure included women who filled at least one prescription in the last 90 days before delivery, irrespective of earlier use. We used early exposure to prescription opioids as a reference to quantify relative risk estimates of neonatal abstinence syndrome for late exposure.

- Total cumulative dose of prescription opioids: in order to quantify the risk of neonatal abstinence syndrome according to the total amount of opioid dispensed, we estimated the cumulative dose of prescription opioids based on all prescriptions for opioid analgesics filled at any time during pregnancy. To facilitate interpretation, opioid dose for all individual prescriptions was converted into oral morphine equivalents ${ }^{34}$ and then accumulated across different prescriptions.

\section{Outcome measurement}

The outcome of interest was a diagnosis of neonatal abstinence syndrome recorded in maternal or infant claims between the delivery date and the 30th day of life for the infant. We used both maternal and infant codes because an infant's claim may be recorded under the mother's identification number for the first several months after birth. The diagnosis of neonatal abstinence syndrome was defined as an ICD-9 CM code 779.5.2

We described the frequency of following complications among cases of neonatal abstinence syndrome using ICD-9-CM codes: preterm delivery, feeding difficulties (779.3), respiratory symptoms (769-770), and signs of seizures $(779.0,780.3)$. We reported the mean length of hospital stay and the frequency of infant admission to neonatal intensive care units among cases of neonatal abstinence syndrome.

\section{Statistical analysis}

Maternal characteristics-including demographics, prevalence of potential prescription opioid indications (pain conditions), individual prescription opioid agents dispensed, and additional risk factors for neonatal abstinence syndrome-were summarized and described for each of the five study groups. The characteristics of prescription opioid exposure, including cumulative days of use and cumulative dose (in oral morphine equivalents), during pregnancy were reported as median (interquartile range). Number of cases and corresponding absolute risks of neonatal abstinence syndrome along with $95 \%$ confidence intervals were presented based on the duration of opioid use (short term and long term use) and timing (early and late use).

For the relative risk estimates, crude risk ratios and 95\% confidence intervals were computed for long term use compared with short term use as well as for late use compared with early use. For risk adjustment, propensity scores were estimated for long term use and late use in separate logistic regression models based on variables including age, geographic region, race, diagnoses of pain conditions, calendar year of delivery, and additional risk factors for neonatal abstinence syndrome. Using a nearest neighbor approach and a caliper width of $0.05,1: 1$ propensity score matching of long term users with short term users and late users with early users was conducted in the whole cohort as well as in each of 
the five study groups to provide adjusted risk ratios for all relevant comparisons. Appendix table 1 contains the statistics for propensity score model fit and propensity score matching efficiency for all the analyses. To account for clustering because of inclusion of multiple deliveries from the same mothers in our cohort, we derived the adjusted risk ratios using generalized estimating equations with a log link and exchangeable working correlation matrix. This approach has been shown to produce reliable estimates in the analysis of repeated pregnancy outcomes. ${ }^{35}$

For the dose-response analysis, logistic regression models were fitted in each of the study groups separately with neonatal abstinence syndrome as the outcome variable and cumulative dose of prescription opioids as the predictor variable. No linearity in the association between cumulative dose of prescription opioids and the risk of neonatal abstinence syndrome was assumed. The dose was modeled as restricted cubic splines with four knots in order to accommodate non-linear relations in the model. ${ }^{36}$ Since short term users of opioids demonstrated very low cumulative use of opioids (the median total cumulative dose for short term users in the entire cohort was equal to $135 \mathrm{mg}$ oral morphine equivalents), we restricted the dose-response analysis to long term users only. Also, owing to the frequent use of illicit opioids among pregnant women with documented history of opioid misuse or dependence, it was not possible to derive accurate cumulative information on opioid exposure in this group. Therefore, we restricted the dose-response analyses to long term users in the other four groups.

Finally, we conducted an additional dose-response analysis using similar methodology for duration of use in which total days of use of prescription opioids during pregnancy was considered as a predictor variable and neonatal abstinence syndrome as the outcome variable. This analysis, defining duration of use as a continuous variable, was designed to evaluate trends in the relation between neonatal abstinence syndrome and duration of opioid use as a supplemental analysis to our main analysis which dichotomized the duration of use into short term ( $<30$ days) and long term ( $\geq 30$ days). All the analyses were conducted using SAS 9.3 (SAS Institute).

\section{Results}

Of 1379450 pregnant women who met the insurance eligibility criteria between 2000 and 2007, we included 290605 (21.1\%) women who filled at least one prescription for an opioid analgesic during pregnancy. Among these, $4816(1.7 \%)$ had a documented history of opioid misuse or dependence (group 1), 28553 (9.8\%) had a history of alcohol or non-opioid drug misuse or dependence (group 2), 34723 (11.9\%) had at least one prescription for a non-opioid psychotropic medication during the 3 months prior to the delivery (group 3), $28512(9.8 \%)$ had a history of smoking (group 4), and $194001(66.5 \%)$ had none of the four hypothesized risk factors for neonatal abstinence syndrome (group 5). The majority of women (256494 or $88.3 \%$ of all users of prescription opioids) used prescription opioids for a short term. Codeine, oxycodone, hydrocodone, and propoxyphene accounted for a majority of the prescription opioid use in each of the five groups (appendix table 2). Table 1 shows the utilization characteristics of use of prescription opioids during pregnancy in our cohort. The median duration of use among short term users ranged from four to six days and the median cumulative dose ranged from $126 \mathrm{mg}$ to $187 \mathrm{mg}$ of oral morphine equivalents across the five study groups. Among long term users, both the median duration of use and cumulative dose within the pregnancy were substantially higher in group 1 (109 days and $4017 \mathrm{mg}$, respectively) than in the other four groups (46 to 64 days and 832 to $1693 \mathrm{mg}$, respectively). Tables 2 and 3

\begin{tabular}{|c|c|c|c|c|}
\hline Population & $\begin{array}{l}\text { Prescription } \\
\text { opioid use } \\
\text { duration* }\end{array}$ & $\begin{array}{l}\text { Total number } \\
\text { (\% of } \\
\text { population) }\end{array}$ & $\begin{array}{l}\text { Cumulative days of } \\
\text { prescription opioid } \\
\text { use during pregnancy } \\
\text { (median (IQR)) }\end{array}$ & $\begin{array}{l}\text { Cumulative dose (in morphine } \\
\text { equivalent mg) of prescription } \\
\text { opioid use during pregnancy } \\
\text { (median (IQR)) }\end{array}$ \\
\hline \multirow[t]{2}{*}{ Whole cohort } & Long term use & $34111(11.7)$ & $55(35-103)$ & $1180(440-2775)$ \\
\hline & Short term use & $256494(88.3)$ & $5(3-8)$ & $135(75-270)$ \\
\hline \multicolumn{5}{|l|}{ Study groups based on hierarchical NAS risk factorst } \\
\hline \multirow[t]{2}{*}{ Group 1: Documented history of opioid drug misuse/dependence } & Long term use & $2139(44.4)$ & $109(56-196)$ & $4017(1579-11388)$ \\
\hline & Short term use & $2677(55.6)$ & $6(3-13)$ & $187(90-442.5)$ \\
\hline \multirow[t]{2}{*}{ Group 2: Documented history of alcohol/non-opioid drug misuse } & Long term use & $4973(17.4)$ & $63(39-123)$ & $1495(620-3390)$ \\
\hline & Short term use & $23580(82.6)$ & $5(3-10)$ & $150(90-316)$ \\
\hline \multirow{2}{*}{$\begin{array}{l}\text { Group 3: Exposure to other psychotropic medications in the third } \\
\text { trimester } \neq\end{array}$} & Long term use & $7027(20.2)$ & $64(39-125)$ & $1613.5(690-3550)$ \\
\hline & Short term use & $27696(79.8)$ & $5(3-11)$ & $162(90-384)$ \\
\hline \multirow[t]{2}{*}{ Group 4: Documented smoking history } & Long term use & $3966(12.9)$ & $54(36-96)$ & $1068(425-2337)$ \\
\hline & Short term use & $24546(87.1)$ & $5(3-10)$ & $145(81-300)$ \\
\hline \multirow[t]{2}{*}{ Group 5: No history of above listed four risk factors } & Long term use & $16006(8.2)$ & $46(34-80)$ & $832(281-1917)$ \\
\hline & Short term use & $177995(91.8)$ & $4(3-8)$ & $126(75-240)$ \\
\hline \multicolumn{5}{|c|}{$\begin{array}{l}\text { IQR=interquartile range, NAS=neonatal abstinence syndrome. } \\
\text { *At least } 30 \text { days of prescription opioids dispensed during pregnancy was defined as long term use, and <30 days as short term use. } \\
\text { tFive mutually exclusive groups were created hierarchically based on the presence of four risk factors. Everyone in group } 1 \text { had a history of opioid misuse/dependence; everyone in group } 2 \text { had } \\
\text { a history of alcohol/non-opioid drug misuse but no opioid misuse or dependence history; everyone in group } 3 \text { had exposure to other psychotropic medications in the third trimester but no } \\
\text { history of opioid misuse/dependence or alcohol/non-opioid drug misuse; everyone in group } 4 \text { had history of smoking but no history of opioid misuse/dependence or alcohol/non-opioid drug } \\
\text { misuse or exposure to other psychotropic medications in the third trimester; and everyone in group } 5 \text { had none of the four identified risk factors. } \\
\neq \text { Other psychotropic medication included were tricyclic antidepressants, selective serotonin re-uptake inhibitors, selective norepinephrine re-uptake inhibitor, benzodiazepines, antipsychotics, } \\
\text { antiepileptics, and non-benzodiazepine sedative hypnotic. }\end{array}$} \\
\hline
\end{tabular}




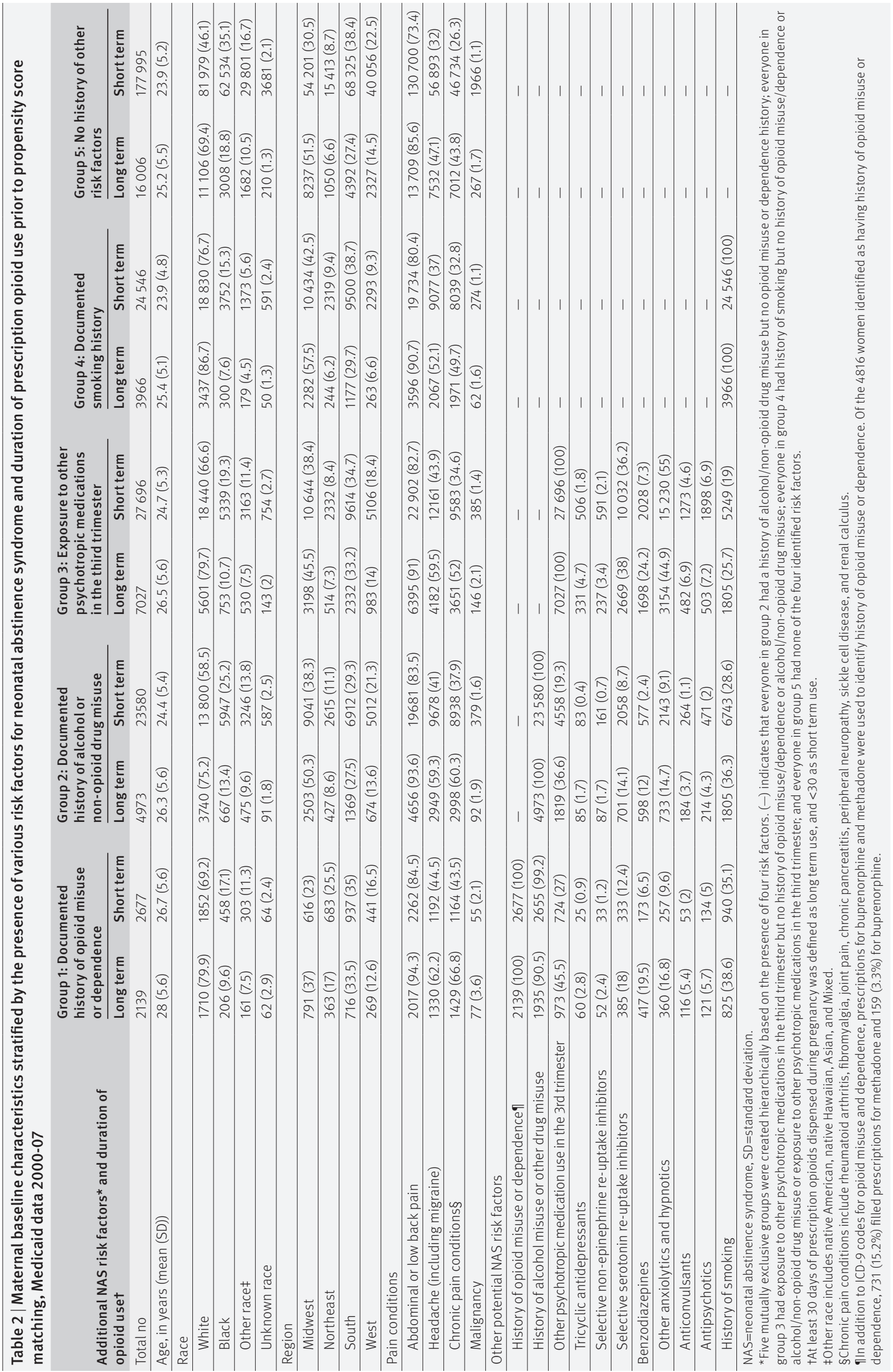


RESEARCH

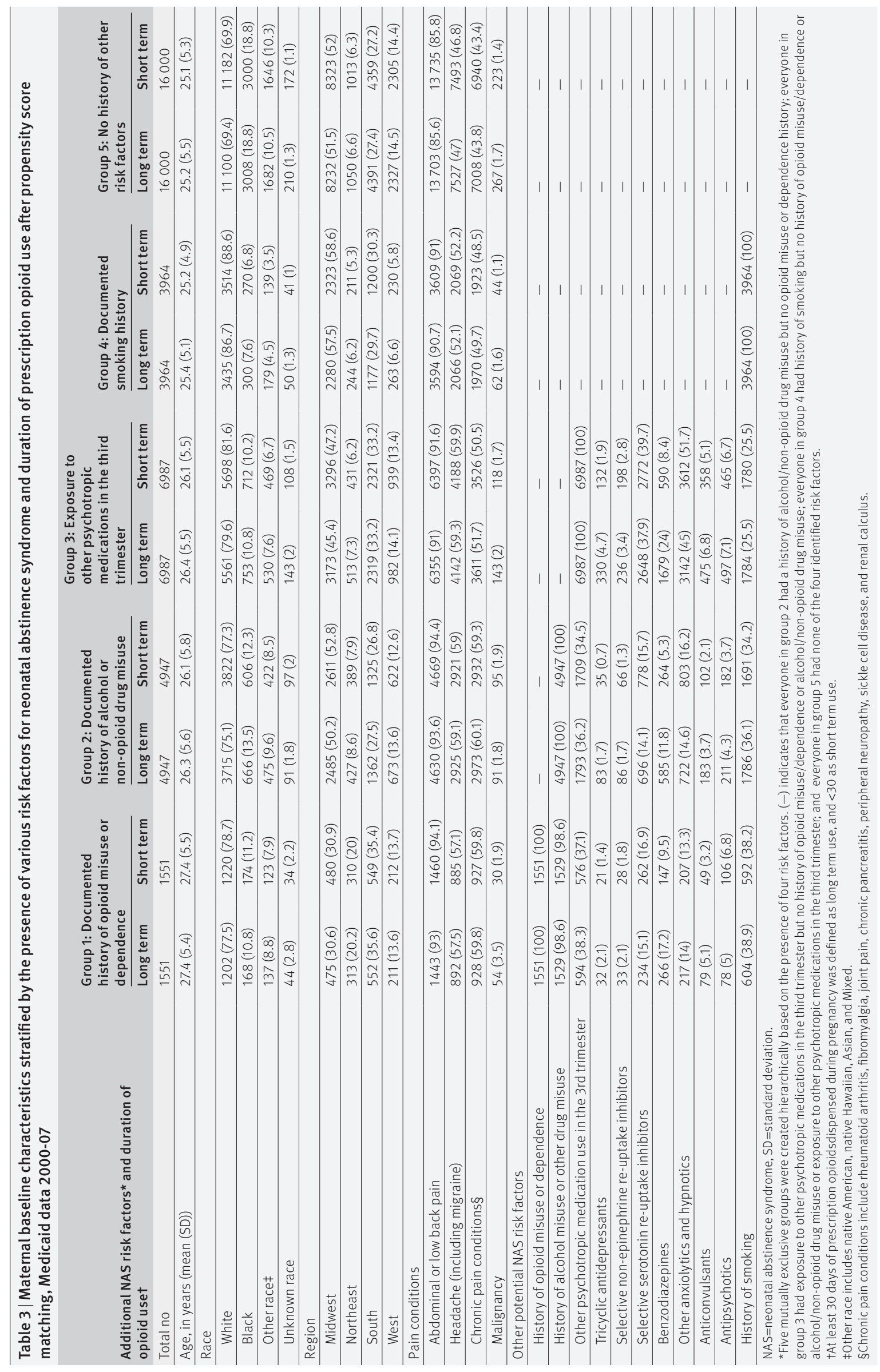

6

doi: 10.1136/bmj.h2102 | BMJ2015;350:h2102 | thelomj 
show baseline maternal characteristics by duration of opioid use before and after propensity score matching in each group, respectively.

A total of 1705 cases of neonatal abstinence syndrome were identified among 290605 pregnant women filling opioid prescriptions, corresponding to an absolute risk of 5.9 per 1000 deliveries (95\% confidence interval 5.6 to 6.2). Absolute risk of neonatal abstinence syndrome was greater among long term users of prescription opioids compared with short term users overall and in each of the five study groups. However, the risk estimates demonstrated substantial variation across the five groups. As expected, risk of neonatal abstinence syndrome was lowest in the group of women with no risk factors (4 cases and $<1$ case per 1000 deliveries for long and short term users, respectively) and highest in the group containing women with a documented history of opioid misuse or dependence (220 and 192 cases per 1000 deliveries for long and short term users, respectively) (table 4). The propensity score adjusted risk ratios demonstrated a significant increase in the risk of neonatal abstinence syndrome after long term exposure compared with short term exposure in the whole cohort (risk ratio 2.05, 95\% confidence interval 1.81 to 2.33), as well as in each of the five study groups (risk ratios ranging from 1.26 to 5.67 ).

Appendix tables 3 and 4 show maternal characteristics by timing of opioid use during pregnancy before and after propensity score matching in each group, respectively. In this comparison between women using opioids through the third trimester (late use) and women who only used opioids in the first two trimesters (early use), a significantly higher risk of neonatal abstinence syndrome was observed among late users (propensity score adjusted risk ratio $1.24,95 \%$ confidence interval 1.12 to 1.38, table 5). This trend was also observed in all study groups (propensity score adjusted risk ratios ranging from 1.48 to 2.50), except for the group with a history of opioid misuse or dependence (propensity score adjusted risk ratio $1.01,95 \%$ confidence interval 0.89 to 1.15 ).

The risk of neonatal abstinence syndrome increased with cumulative dose of opioids during pregnancy for long term users in all the study groups considered for this analysis, reaching a plateau at higher cumulative doses (fig 1). Consistent with observations in tables 3 and $4^{4}$, higher predicted risk of neonatal abstinence syndrome was observed with presence of the additional risk factors of smoking, other psychotropic medications, and alcohol or other drug misuse at similar levels of doses of prescription opioids. Appendix table 5 shows risk estimates for neonatal abstinence syndrome at various levels of cumulative opioid doses in each of these groups. Similarly, the supplemental doseresponse analysis, which defined duration of use as a continuous variable, indicated increased risk of neonatal abstinence syndrome with an increase in the number of days of exposure to prescription opioids during pregnancy (appendix fig 1).

Respiratory symptoms and feeding difficulties were frequently observed ( $30.1 \%$ and $17.1 \%$, respectively), while incidence of seizures was rare (2.7\%) among the 1705 observed cases of neonatal abstinence syndrome. The mean (standard deviation) length of hospitalization for these cases was five (7) days, while for non-cases it was three (3) days. Preterm delivery occurred in 734 (37.2\%) of infants affected by neonatal abstinence syndrome and 37347 (12.9\%) of non-affected infants in our cohort. Additional descriptive characteristics of cases of neonatal abstinence syndrome are summarized in appendix table 6 stratified by the duration of opioid use.

\section{Discussion}

\section{Principal findings}

In this large population based cohort study, we observed a low absolute risk of neonatal abstinence

\begin{tabular}{|c|c|c|c|c|c|c|}
\hline \multirow[b]{2}{*}{ Population } & \multicolumn{2}{|c|}{$\begin{array}{l}\text { Total NAS cases/sample } \\
\text { size }\end{array}$} & \multicolumn{2}{|c|}{$\begin{array}{l}\text { Absolute NAS risks per } 1000 \text { deliveries } \\
(95 \% \mathrm{CI}) \text { based on duration of prescription } \\
\text { opioid use }\end{array}$} & \multicolumn{2}{|c|}{$\begin{array}{l}\text { Relative risks }(95 \% \mathrm{Cl}) \text { for long term } v \\
\text { short term prescription opioid use }\end{array}$} \\
\hline & Long term* & Short term* & Long term & Short term & Unadjusted & Adjustedt \\
\hline Whole cohort & $810 / 34111$ & $895 / 256494$ & 23.7 (22.1 to 25.4$)$ & 3.5 (3.3 to 3.7$)$ & 6.81 (6.19 to 7.48$)$ & 2.05 (1.81 to 2.33$)$ \\
\hline \multicolumn{7}{|l|}{ Study groups based on hierarchical NAS risk factorsł } \\
\hline $\begin{array}{l}\text { Group 1: Documented history of opioid drug } \\
\text { misuse/dependence }\end{array}$ & 471/2139 & $514 / 2677$ & 220.2 (200.8 to 241) & 192.0 (175.8 to 209.3) & 1.15 (1.03 to 1.28$)$ & 1.26 (1.09 to 1.45$)$ \\
\hline $\begin{array}{l}\text { Group 2: Documented history of alcohol/ } \\
\text { non-opioid drug misuse }\end{array}$ & $153 / 4973$ & $166 / 23580$ & 30.8 (26.1 to 36$)$ & $7.0(6.0$ to 8.2$)$ & 4.37 (3.52 to 5.43$)$ & 4.90 (3.34 to 7.2$)$ \\
\hline $\begin{array}{l}\text { Group 3: Exposure to other psychotropic } \\
\text { medications§ in the third trimester }\end{array}$ & $92 / 7027$ & $56 / 27696$ & 13.1 (10.6 to 16.1) & $2.0(1.5$ to 2.6$)$ & 6.48 (4.65 to 9.02$)$ & $3.81(2.44$ to 5.95$)$ \\
\hline Group 4: Documented smoking history & $26 / 3966$ & $36 / 24546$ & $6.6(4.3$ to 9.6$)$ & $1.5(1$ to 2$)$ & $4.47(2.7$ to 7.39$)$ & 3.71 (1.61 to 8.55$)$ \\
\hline Group 5: No history ofour above listed f risk factors & $68 / 16006$ & $123 / 177995$ & $4.2(3.3$ to 5.4$)$ & 0.7 (0.6 to 0.8$)$ & 6.15 (4.57 to 8.26) & 5.67 (3.07 to 10.47) \\
\hline \multicolumn{7}{|c|}{$\begin{array}{l}\text { NAS=neonatal abstinence syndrome, } \mathrm{Cl}=\text { confidence interval. } \\
\text { *At least } 30 \text { days of prescription opioids dispensed during pregnancy was defined as long term use and <30 days as short term use. } \\
\text { †Propensity score (PS) matching of long term users with short term users was used to adjust for confounding factors including age, geographic region, race, pain condition diagnoses, calendar } \\
\text { year of delivery, and other NAS risk factors. Risk ratios derived using generalized estimating equations with log link and exchangeable working correlation matrix to account for clustering owing } \\
\text { to inclusion of mothers with multiple deliveries in the cohort. } \\
\text { fFive mutually exclusive groups were created hierarchically based on the presence of four risk factors. Everyone in group } 1 \text { had a history of opioid misuse/dependence; everyone in group } 2 \text { had } \\
\text { a history of alcohol/non-opioid drug misuse but no opioid misuse or dependence history; everyone in group } 3 \text { had exposure to other psychotropic medications in the third trimester but no } \\
\text { history of opioid misuse/dependence or alcohol/non-opioid drug misuse; everyone in group } 4 \text { had history of smoking but no history of opioid misuse/dependence or alcohol/non-opioid drug } \\
\text { misuse or exposure to other psychotropic medications in the third trimester; and everyone in group } 5 \text { had none of the four identified risk factors. } \\
\text { §Other psychotropic medication included were tricyclic antidepressants, selective serotonin re-uptake inhibitors, selective nor epinephrine re-uptake inhibitor, benzodiazepines, } \\
\text { antipsychotics, antiepileptics, and non-benzodiazepine sedative hypnotic. }\end{array}$} \\
\hline
\end{tabular}




\begin{tabular}{|c|c|c|c|c|c|c|}
\hline \multirow[b]{2}{*}{ Population } & \multicolumn{2}{|c|}{ Total NAS cases/sample size } & \multicolumn{2}{|c|}{$\begin{array}{l}\text { Absolute NAS risks per } 1000 \text { deliveries }(95 \% \mathrm{Cl}) \\
\text { based on timing of prescription opioid use }\end{array}$} & \multicolumn{2}{|c|}{$\begin{array}{l}\text { Relative risks }(95 \% \mathrm{Cl}) \text { for late } v \text { early } \\
\text { prescription opioid use }\end{array}$} \\
\hline & Late use* & Early use* & Late use & Early use & Unadjusted & Adjustedt \\
\hline Whole cohort & $1042 / 134361$ & $663 / 156244$ & $7.8(7.3$ to 8.2$)$ & $4.2(3.9$ to 4.6$)$ & $1.83(1.66$ to 2.01$)$ & $1.24(1.12$ to 1.38$)$ \\
\hline \multicolumn{7}{|c|}{ Study groups based on hierarchical NAS risk factorsł } \\
\hline $\begin{array}{l}\text { Group 1: Documented history of opioid } \\
\text { drug abuse/dependence }\end{array}$ & $571 / 2836$ & $414 / 1980$ & 201.3 (185.2 to 218.6$)$ & 209.1 (189.4 to 230.2) & $0.96(0.86$ to 1.08$)$ & 1.01 (0.89 to 1.15$)$ \\
\hline $\begin{array}{l}\text { Group 2: Documented history of alcohol/ } \\
\text { non-opioid drug abuse }\end{array}$ & $211 / 14144$ & $108 / 14409$ & 14.9 (13 to 17.1$)$ & 7.5 (6.1 to 9.0) & $1.99(1.58$ to 2.51$)$ & 1.74 (1.35 to 2.25$)$ \\
\hline $\begin{array}{l}\text { Group 3: Exposure to other psychotropic } \\
\text { medications§ in the third trimester }\end{array}$ & $120 / 20775$ & $28 / 13948$ & $5.8(4.8$ to 6.9$)$ & $2.0(1.3$ to 2.9$)$ & $2.88(1.91$ to 4.34$)$ & 2.50 (1.61 to 3.87$)$ \\
\hline Group 4: Documented smoking history & $38 / 13366$ & $24 / 15146$ & 2.8 (2 to 3.9$)$ & $1.6(1.0$ to 2.4$)$ & 1.79 (1.08 to 2.99) & 1.85 (1.07 to 3.19) \\
\hline $\begin{array}{l}\text { Group 5: No history of above listed four } \\
\text { risk factors }\end{array}$ & $102 / 83240$ & $89 / 110761$ & $1.2(1$ to 1.5$)$ & $0.8(0.6$ to 1.0$)$ & $1.53(1.15$ to 2.03$)$ & $1.48(1.09$ to 2.01$)$ \\
\hline
\end{tabular}

NAS=neonatal abstinence syndrome, $\mathrm{Cl}=$ confidence interval.

*Early use included filled prescriptions only in the first two trimesters but no newly dispensed opioid prescription in the last 90 days before delivery; late use included at least one filled prescription in the last 90 days before delivery, irrespective of earlier use.

tPropensity score (PS) matching of late users with early users was used to adjust for confounding factors including age, geographic region, race, pain condition diagnoses, calendar year of delivery, and other NAS risk factors. Risk ratios derived using generalized estimating equations with log link and exchangeable working correlation matrix to account for clustering due to inclusion of mothers with multiple deliveries in the cohort.

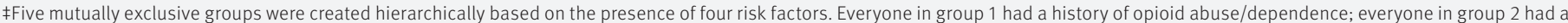
history of alcohol/non-opioid drug abuse but no opioid abuse or dependence history; everyone in group 3 had exposure to other psychotropic medications in the third trimester but no history of opioid abuse/dependence or alcohol/non-opioid drug abuse; everyone in group 4 had history of smoking but no history of opioid abuse/dependence or alcohol/non-opioid drug abuse or exposure to other psychotropic medications in the third trimester; and everyone in group 5 had none of the four identified risk factors.

$\S 0 t h e r$ psychotropic medication included were tricyclic antidepressants, selective serotonin re-uptake inhibitors, selective nor epinephrine re-uptake inhibitor, benzodiazepines,

antipsychotics, antiepileptics, and non-benzodiazepine sedative hypnotic.

syndrome after in utero exposure to prescription opioids in the absence of additional risk factors. The absolute risk of neonatal abstinence syndrome after in utero exposure to prescription opioids was highest in the presence of history of opioid misuse or dependence, followed by alcohol or other drug misuse, exposure to non-opioid psychotropic medications, and smoking. Long term use of prescription opioids during pregnancy compared with short term use and use in late pregnancy compared with early pregnancy increased risk of neonatal abstinence syndrome independent of additional risk factors.
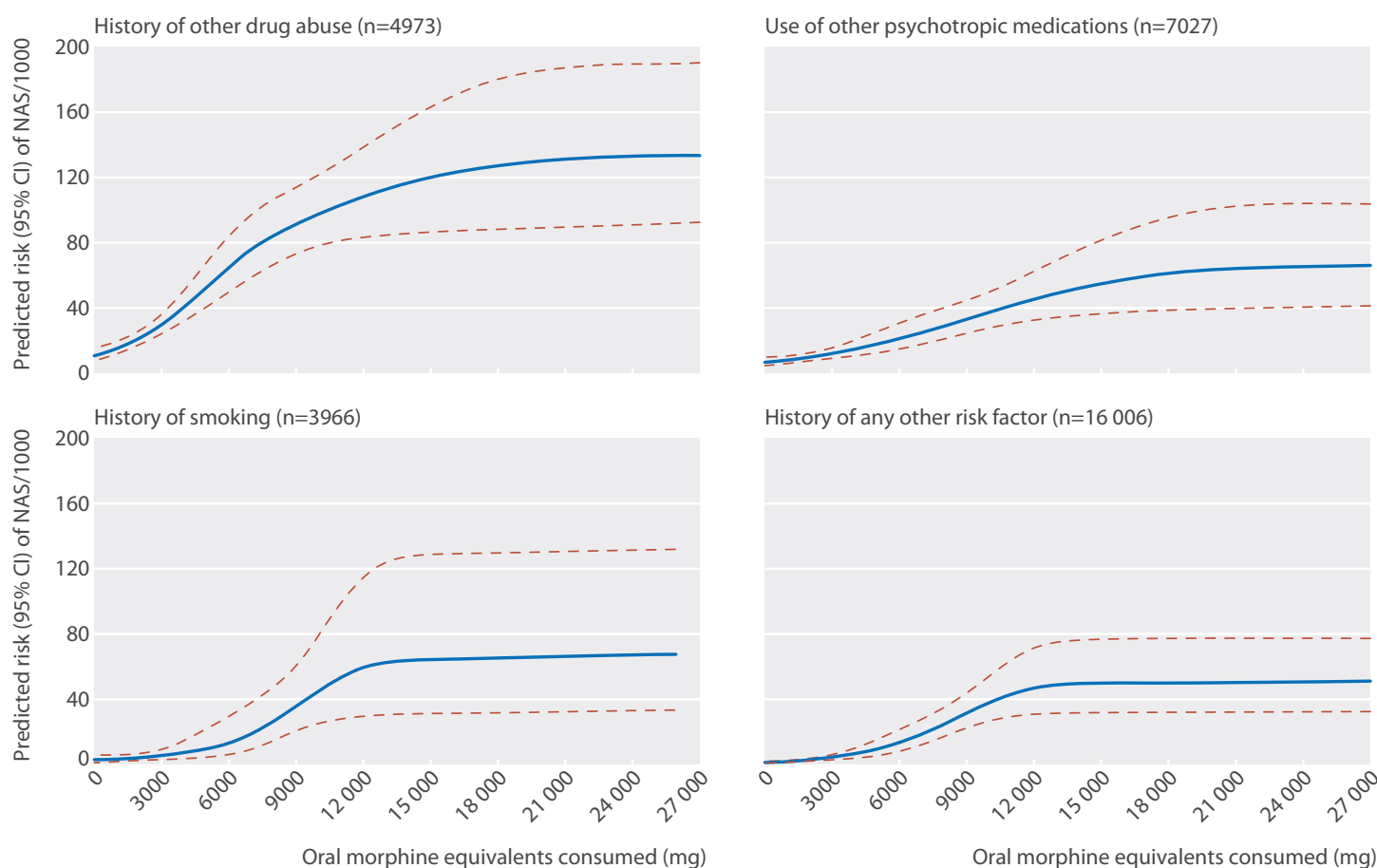

Oral morphine equivalents consumed (mg)

Risk of neonatal abstinence syndrome (NAS) according to cumulative opioid consumed (in morphine equivalent milligrams) during pregnancy in long term users of prescription opioids, Medicaid data 2000-07. *Blue lines denote absolute risk estimates, red lines denote $95 \%$ confidence intervals 


\section{Comparison with other studies}

The current study expands upon our limited understanding of the risk of neonatal abstinence syndrome in infants after use of prescription opioids by mothers during pregnancy. To date, this outcome has been evaluated only in one cohort study of 167 pregnant women with long term use of prescription opioids (defined as use for at least 30 days) and that study noted incidence of neonatal abstinence syndrome in $5.6 \%$ of the delivered infants. ${ }^{18}$ The corresponding number in our study is $2.4 \%$ (810 cases/34111 long term users combined across the five groups). This difference in magnitude may be because of dissimilar prevalence of other risk factors for neonatal abstinence syndrome between the two studies. Additionally, in the previous study, ascertainment of neonatal abstinence syndrome occurred on the basis of clinical parameters by neonatology staff, while in the current study ascertainment was based on ICD-9 codes. Therefore, the difference may also be due to the severity of the cases of neonatal abstinence syndrome; we expect the neonatal abstinence syndrome ICD-9 code to be applied in circumstances in which neonatal abstinence syndrome affects the clinical course of the affected infant, whereas the earlier study may classify very mild cases as neonatal abstinence syndrome based on sensitive clinical parameters.

The risk of neonatal withdrawal symptoms in infants born to women dependent on opioids, either using illicit opioids or using medication assisted maintenance therapy, is reported in several prior studies with limited sample sizes. In a cohort of 50 women who used illicit heroin during pregnancy, Alroomi and colleagues ${ }^{4}$ reported signs of drug withdrawal in 21 (42\%) infants, nine $(18 \%)$ of whom experienced symptoms that were severe enough to warrant treatment. In a randomized control trial comparing outcomes between methadone and buprenorphine maintenance therapy for treatment of opioid dependence in 131 pregnant women, $57 \%$ and $47 \%$ of the infants were reported to have required treatment for neonatal abstinence syndrome in the methadone and buprenorphine groups, respectively. ${ }^{5}$ In the current study, we observed 985 (20.4\%) infants with a recorded diagnosis of neonatal abstinence syndrome among 4816 women with documented history of opioid dependence or misuse who used at least one prescription opioid during pregnancy. While our findings are in line with the comparable findings from Alroomi and colleagues, ${ }^{4}$ the difference between our estimates and the estimates reported in the randomized trial ${ }^{5}$ may reflect the possibility of different patient populations included and differential intensities of follow-up for the diagnosis of neonatal abstinence syndrome in these two studies. Of note, in our study only $18.5 \%$ of the 4816 women actively received prescriptions for methadone or buprenorphine (table 1), while in the randomized trial $100 \%$ of the included women were on one of these two treatments. The trial also had a mandatory observation period of 10 days after birth for evaluation of neonatal abstinence syndrome, which may not be the case for the infants observed in the current study and hence it is possible that the incidence of neonatal abstinence syndrome reported in the current study may underestimate the actual incidence.

This study is the first one to our knowledge that evaluates a dose-response relation between use of prescription opioids and the risk of neonatal abstinence syndrome. We observed that the risk of neonatal abstinence syndrome increased with higher doses of opioids during pregnancy for long term users, but reached a plateau at higher cumulative doses. This observation is consistent with results from a large meta-analysis, which indicated that at higher doses of methadone maintenance therapy there was no further dose-dependent increase in the risk of neonatal abstinence syndrome. ${ }^{37}$ While we excluded women with known opioid misuse or dependence from this analysis owing to the unavailability of reliable data from illicit sources on opioid exposure, our results suggest that prior findings of limited effectiveness of a dose reduction of methadone, after a certain point of cumulative exposure, in reducing the risk of neonatal abstinence syndrome may extend to prescription non-maintenance opioids.

\section{Clinical implications}

The current study provides some important clinical implications. Our observation of greater risk of neonatal abstinence syndrome in babies born to long term users of prescription opioids suggests that clinicians should carefully weigh benefits and risks of long term opioid use to the developing fetus. Since long term use through the third trimester appears to impart greater risk of neonatal abstinence syndrome, minimizing the use of prescription opioids towards the end of pregnancy, when clinically reasonable, may be a strategy to reduce this risk. The use of prescription opioids in concomitance with other risk factors such as non-opioid psychotropic agents and smoking should also be carefully considered and balanced against the presence of clinical conditions that may necessitate opioid use for pain control. On the other hand, the benefits from the short term use of prescription opioids in treating acute pain in the absence of additional risk factors during pregnancy may outweigh the potential risk of neonatal abstinence syndrome, since short term use of prescription opioids during pregnancy appears to result in a relatively low risk of neonatal abstinence syndrome. Prior research indicates that untreated pain in pregnancy is common and may lead to limited productivity and difficulties in activities of daily living. ${ }^{38}$ While evaluating the risk-benefit balance of prescription opioid treatment in pregnancy, it should also be noted that neonatal abstinence syndrome is a condition that is identifiable and treatable with pharmacological and non-pharmacological approaches. ${ }^{1}$

\section{Strengths and limitations}

Our study has several strengths. First, the large sample size enabled us to stratify and evaluate the risk of neonatal abstinence syndrome based on the presence of 
additional risk factors and duration of opioid use. This approach allowed us to conclude that the absolute risk of neonatal abstinence syndrome associated with opioid use depends on the patient characteristics (for instance, smoking and use of other psychotropics) as well as on the patterns of opioid use (for instance, misuse, duration, and proximity to delivery). Next, owing to the availability of prescription claims data, we were able to quantify the amount of total prescription opioids dispensed and conduct dose-response analyses for risk of neonatal abstinence syndrome.

Our study also has some limitations. First and foremost, our data source only captures prescriptions filled by women in an outpatient setting. Any inpatient opioid use is therefore not accounted for, which may result in an underestimation of real use. We also did not have information on the amount of illicit opioid use for women with a history of opioid misuse or dependence. Prescription opioids are likely just one component of the opioids these women are exposed to and the weak association for long term versus short term use and lack of association for late versus early use of prescription opioids in this group (tables 3 and 4) likely reflects the lack of measurement of use of illicit opioids for this group in our data. Use of pharmacy dispensing data to quantify the amount and timing of opioid use also has limitations because it requires the assumption that women consumed all the dispensed opioids in the interval for which they were filled.

Second, we relied on ICD-9 diagnosis codes to determine the outcome of neonatal abstinence syndrome. While we expect that infants with severe neonatal abstinence syndrome which impacts their clinical course would be assigned the ICD-9 code for this condition, it is possible that infants with milder symptoms may not carry the code, which may result in an underestimation of actual risk of neonatal abstinence syndrome. Owing to the unavailability of more detailed measures of neonatal abstinence syndrome, such as the Finnegan scale, this study does not shed any light on the severity of neonatal abstinence syndrome. Further, we relied on ICD-9 codes and relevant pharmacy claims recorded during pregnancy to identify maternal risk factors for neonatal abstinence syndrome. This approach may result in some misclassification of our risk factor based grouping owing to underestimation of the risk factors such as smoking; that said, we have comprehensive capture of diagnostic codes from inpatient and outpatient records throughout pregnancy, a period during which patients are under close surveillance for conditions that are expected to impact pregnancy. It is thus likely that we identified most pregnancies with these risk factors accurately.

Next, our sample consisted of Medicaid enrolled women, who mainly represent women of lower socioeconomic status in the US. The prevalence of certain risk factors for neonatal abstinence syndrome, such as smoking and drug misuse, as well as rates of prescription opioid use may be different in women with higher socioeconomic status. Therefore, the reported absolute risk of neonatal abstinence syndrome in the overall cohort may not be generalizable to other populations.
The analyses of the effect of dose, timing, and duration of use are attempting to identify a biological effect of opioid exposure on the risk of neonatal abstinence syndrome and therefore should be generalizable to other populations. Finally, we used prescriptions of methadone and buprenorphine to identify women with opioid dependence. Although primarily used for medication assisted maintenance, these agents are also sometimes used for pain control. Therefore, some misclassification of women in the groups for opioid dependence or misuse is possible.

\section{Conclusions}

Findings from this study indicate that long term use of prescription opioids compared with short term use and late use compared with early use are associated with increased risk of neonatal abstinence syndrome independent of additional risk factors. Additional risk factors such as history of opioid misuse or dependence, alcohol or other drug misuse, exposure to other psychotropic medications late in pregnancy, and smoking contribute to greater risk of neonatal abstinence syndrome among infants exposed in utero to prescription opioids. Clinicians should carefully consider the presence of one or more of these risk factors in pregnant women and try to minimize the long term use of prescription opioids when clinically viable. Short term use of prescription opioids during pregnancy in the absence of additional risk factors is associated with a very low absolute risk of neonatal abstinence syndrome.

Contributors: RJD, KFH, SHD, and BTB contributed to all the aspects of this study. HM was involved in preparation of analytic datasets and designing the study. EP, KK, and LSK were involved in designing the study and preparation of the final manuscript. All authors had full access to all of the data (including statistical reports and tables) in the study and take responsibility for the integrity of the data and the accuracy of the data analysis. RJD and BTB are the guarantors.

Funding: This study was not funded by any external institution.

Competing interests: All authors have completed the ICMJE uniform disclosure form at www.icmje.org/coi_disclosure.pdf and declare: $\mathrm{KH}$ is supported by a career development award from the National Institute of Mental Health (K01 MH099141); BB is supported by a career development award from the Eunice Kennedy Shriver National Institute of Child Health and Human Development of the NIH (K08HD075831). MAX pregnancy cohort creation was supported by the Agency for Healthcare Research and Quality (AHRQ) (Grant R01HS018533). SH-D has consulted for GlaxoSmithKline-Biologics (Middlesex, UK) and AstraZeneca (London, UK) for unrelated projects. The other authors declare no other relationships or activities that could appear to have influenced the submitted work.

Ethical approval: This use of this de-identified database for research was approved by the institutional review board of the Brigham and Women's Hospital, Boston, MA, and a data use agreement was in place.

Data sharing: no additional data available.

RJD and BTB affirm that the manuscript is an honest, accurate, and transparent account of the study being reported; that no important aspects of the study have been omitted; and that any discrepancies from the study as planned (and, if relevant, registered) have been explained

This is an Open Access article distributed in accordance with the Creative Commons Attribution Non Commercial (CC BY-NC 4.0) license, which permits others to distribute, remix, adapt, build upon this work non-commercially, and license their derivative works on different terms, provided the original work is properly cited and the use is non-commercial. See: http://creativecommons.org/licenses/ by-nc/4.0/. 
1 Jansson LM, Velez M. Neonatal abstinence syndrome. Curr Opin Pediatr 2012;24:252-8.

2 Patrick SW, Schumacher RE, Benneyworth BD, Krans EE, McAllister JM, Davis MM. Neonatal abstinence syndrome and associated health care expenditures: United States, 2000-2009. JAMA 2012;307:1934-40.

3 Creanga AA, Sabel IC, Ko IY et al. Maternal drug use and its effect on neonates: a population-based study in Washington State. Obstet Gynecol 2012;119:924-33.

4 Alroomi LG, Davidson J, Evans TJ, Galea P, Howat R. Maternal narcotic misuse and the newborn. Arch Dis Child 1988;63:81-3.

5 Jones HE, Kaltenbach K, Heil SH, et al. Neonatal abstinence syndrome after methadone or buprenorphine exposure. N Engl / Med 2010;363:2320-31.

6 Sharpe C, Kuschel C. Outcomes of infants born to mothers receiving methadone for pain management in pregnancy. Arch Dis Child 2004;89:F33-6.

7 Engeland A, Bramness IG, Daltveit AK, Rønning M, Skurtveit S, Furu K. Prescription drug use among fathers and mothers before and during pregnancy. A population-based cohort study of 106,000 pregnancies in Norway 2004-2006. Br J Clin Pharmacol 2008;65:653-60.

8 Desai RJ, Hernandez-Diaz S, Bateman BT, Huybrechts KF. Increase in prescription opioid use during pregnancy among Medicaid-enrolled women. Obstet Gynecol 2014;123:997-1002.

9 Bateman BT, Hernandez-Diaz S, Rathmell JP, et al. Patterns of opioid utilization in pregnancy in a large cohort of commercial insurance beneficiaries in the United States. Anesthesiology 2014;120:1216-24.

10 Fischer B, Jones W, Krahn M, Rehm J. Differences and over-time changes in levels of prescription opioid analgesic dispensing from retail pharmacies in Canada, 2005-2010. Pharmacoepidemiol Drug Saf 2011;20:1269-77.

11 Schubert I, Ihle P, Sabatowski R. Increase in opiate prescription in Germany between 2000 and 2010: a study based on insurance data. Dtsch Arztebl Int 2013;110:45-51.

12 Ponizovsky AM, Marom E, Zeldin A, Cherny NI. Trends in opioid analgesics consumption, Israel, 2000-2008. Eur / Clin Pharmacol 2011:67:165-8.

13 Zin CS, Chen LC, Knaggs RD. Changes in trends and pattern of strong opioid prescribing in primary care. Eur J Pain 2014;18:1343-51.

14 Nair V, Soraisham AS, Akierman A. Neonatal withdrawal syndrome due to maternal codeine use. Paediatr Child Health 2012;17:e40-1

15 Mangurten HH, Benawra R. Neonatal codeine withdrawal in infants of nonaddicted mothers. Pediatrics 1980;65:159-60.

16 Willaschek C, Wolter E, Buchhorn R. Tramadol withdrawal in a neonate after long-term analgesic treatment of the mother. Eur J Clin Pharmacol 2009;65:429-30.

17 Hartenstein S, Proquitte H, Bauer S, Bamberg C, Roehr CC Neonatal abstinence syndrome (NAS) after intrauterine exposure to tramadol. J Perinat Med 2010;38:695-6

18 Kellogg A, Rose CH, Harms RH, Watson WJ. Current trends in narcotic use in pregnancy and neonatal outcomes. Am I Obstet Gynecol 2011;204:259 e1-4.

19 Coles CD, Platzman KA, Smith I, James ME, Falek A. Effects of cocaine and alcohol use in pregnancy on neonatal growth and neurobehavioral status. Neurotoxicol Teratol 1992;14:23-33.

20 Mayes LC, Carroll KM. Neonatal withdrawal syndrome in infants exposed to cocaine and methadone. Subst Use Misuse 1996:31:241-53.

21 Dryden C, Young D, Hepburn M, Mactier H. Maternal methadone use in pregnancy: factors associated with the development of neonata abstinence syndrome and implications for healthcare resources. BJOG 2009;116:665-71.

22 Jansson LM, Di Pietro JA, Elko A, Williams EL, Milio L, Velez M. Pregnancies exposed to methadone, methadone and other illicit substances, and poly-drugs without methadone: a comparison of fetal neurobehaviors and infant outcomes. Drug Alcohol Depend 2012;122:213-9.
23 Moore SJ, Turnpenny P, Quinn A, et al. A clinical study of 57 children with fetal anticonvulsant syndromes. J Med Genet 2000;37:489-97.

24 Wachman EM, Newby PK, Vreeland J, et al. The relationship between maternal opioid agonists and psychiatric medications on length of hospitalization for neonatal abstinence syndrome. J Addict Med 2011:5:293-9.

25 Sanz EJ, De-las-Cuevas C, Kiuru A, Bate A, Edwards R. Selective serotonin reuptake inhibitors in pregnant women and neonatal withdrawal syndrome: a database analysis. Lancet 2005;365:482-7.

26 Choo RE, Huestis MA, Schroeder JR, Shin AS, Jones HE. Neonatal abstinence syndrome in methadone-exposed infants is altered by level of prenatal tobacco exposure. Drug Alcohol Depend 2004;75:253-60.

27 O’Donnell M, Nassar N, Leonard H, et al. Increasing prevalence of neonatal withdrawal syndrome: population study of maternal factors and child protection involvement. Pediatrics 2009;123:e614-21

28 Kaltenbach $\mathrm{K}$, Holbrook AM, Coyle MG, et al. Predicting treatment for neonatal abstinence syndrome in infants born to women maintained on opioid agonist medication. Addiction 2012;107:45-52.

29 Palmsten K, Huybrechts KF, Mogun H, et al. Harnessing the Medicaid Analytic eXtract (MAX) to evaluate medications in pregnancy: design considerations. PloS One 2013;8:e67405.

30 Margulis AV, Setoguchi S, Mittleman MA, Glynn RJ, Dormuth CR, Hernandez-Diaz S. Algorithms to estimate the beginning of pregnancy in administrative databases. Pharmacoepidemiol Drug Saf 2013;22:16-24.

31 Osborn DA, Jeffery HE, Cole MJ. Opiate treatment for opiate withdrawal in newborn infants. Cochrane Database Syst Rev 2010:CD002059

32 Babb M, Koren G, Einarson A. Treating pain during pregnancy. Can Fam Physician 2010:56:25, 27.

33 Flood P, Raja SN. Balance in opioid prescription during pregnancy. Anesthesiology 2014;120:1063-4

34 Logan J, Liu Y, Paulozzi L, Zhang K, Jones C. Opioid prescribing in emergency departments: the prevalence of potentially inappropriate prescribing and misuse. Med care 2013;51:646-53

35 Louis GB, Dukic V, Heagerty PJ, et al. Analysis of repeated pregnancy outcomes. Stat Methods Med Res 2006;15:103-26.

36 Harrell FE. Regression modeling strategies: with applications to linear models, logistic regression, and survival analysis. Springer, 2001

37 Cleary BJ, Donnelly J, Strawbridge J, et al. Methadone dose and neonatal abstinence syndrome-systematic review and meta-analysis. Addiction 2010;105:2071-84

38 Wang SM, Dezinno P, Maranets I, Berman MR, Caldwell-Andrews AA Kain ZN. Low back pain during pregnancy: prevalence, risk factors, and outcomes. Obstet Gynecol 2004;104:65-70.

(C) BMJ Publishing Group Ltd 2015

Web appendix: Supplementary material Web figure: Risk of neonatal abstinence syndrome (NAS) according to cumulative duration of exposure (in days) to prescription opioids during pregnancy, Medicaid data 2000-07. *Footnote: Blue lines denote absolute risk estimates, red lines denote $95 \%$ confidence intervals. 